Research Article

\title{
Fabrication of N-Doped Graphene@TiO2 Nanocomposites for Its Adsorption and Absorbing Performance with Facile Recycling
}

\author{
Pravin Onkar Patil ${ }^{1}$, Sopan Namdev Nangare ${ }^{1}$, Pratiksha Pramod Patil ${ }^{1}$, Ashwini Ghanashyam \\ Patil $^{2}$, Dilip Ramsing Patil ${ }^{2}$, Rahul Shankar Tade ${ }^{1}$, Arun Madhukar Patil ${ }^{2}$, Prashant Krishnarao \\ Deshmukh$^{3}$, Sanjay Baburao Bari ${ }^{1}$ \\ ${ }^{1}$ H.R. Patel Institute of Pharmaceutical Education and Research, Karvand Naka, Shirpur, Dist- Dhule, Maharashtra, 425405 India. \\ ${ }^{2}$ R.C. Patel Arts, Science, and Commerce College, Shirpur, Maharashtra, 425405 India. \\ ${ }^{3}$ Dr. Rajendra Gode College of Pharmacy, Malkapur, Dist- Buldhana, Maharashtra, 443101 India.
}

Corresponding author. E-mail: rxpatilpravin@yahoo.co.in

Received: Dec. II, 2020; Accepted: Mar. 29, 2021; Published: May 26, 2021

Citation: Pravin Onkar Patil, Sopan Namdev Nangare, Pratiksha Pramod Patil, Ashwini Ghanashyam Patil, Dilip Ramsing Patil, Rahul Shankar

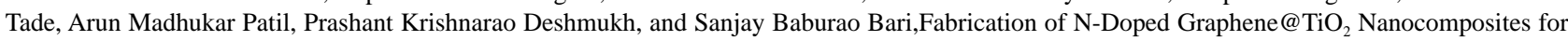
Its Adsorption and Absorbing Performance with Facile Recycling. Nano Biomed. Eng., 202।, I3(2): I79-I90.

DOI: $10.5101 /$ nbe.v13i2.p179-190.

\begin{abstract}
The present work aims to synthesize nitrogen-doped reduced graphene oxide-titanium dioxide nanocomposite (N-rGO@ $\mathrm{TiO}_{2}$ ) using a simple, eco-friendly method and its applications in spectroscopic detection of heavy metal ions such as lead $\left(\mathrm{Pb}^{2+}\right)$, mercury $\left(\mathrm{Hg}^{2+}\right)$, and chromium-VI [Cr(VI)] in potable water. Initially, $\mathrm{TiO}_{2}$ nanoparticles loaded $\mathrm{N}$ doped $\mathrm{rGO}$ sheets were fabricated by an ecological method using Gossypium hirsutum (cotton) seeds extract as a green reducing agent. Then, the N-rGO@ $\mathrm{TiO}_{2}$ nanocomposites were subjected for characterizations such as spectroscopic techniques, particle size analysis, zeta potential analysis, and spectroscopic sensing. Notably, the results of this study confirmed that $\mathrm{N}-\mathrm{rGO} @ \mathrm{TiO}_{2}$ exhibited countless stupendous features in terms of sensing of an analyte. Briefly, the UV-visible spectroscopy and Fourier transform infrared (FTIR) spectroscopy confirmed the successful synthesis of N-rGO@TiO . The SEM images showed the wrinkled, folded, and cross-linked network structures that confirmed the surface modification and nitrogen doping in the rGO sheet and synthesis of N-rGO@TiO ${ }_{2}$. The EDAX study confirmed the elemental composition of the $\mathrm{N}-\mathrm{rGO} @ \mathrm{TiO}_{2}$ nanocomposite. Finally, due to the larger surface area, porous nature, high electron mobility, etc. the $\mathrm{N}-\mathrm{rGO} @ \mathrm{TiO}_{2}$ probe provides the lower detection limit for $\mathrm{Pb}^{2+}, \mathrm{Hg}^{2+}$ and $\mathrm{Cr}(\mathrm{VI})$ as low as $50 \mathrm{nM}, 15 \mu \mathrm{M}$, and $25 \mathrm{nM}$, respectively. Concisely, our study affirms the admirable sensitivity of $\mathrm{N}-\mathrm{rGO} @ \mathrm{TiO}_{2}$ nanocomposite to the $\mathrm{Pb}^{2+}, \mathrm{Hg}^{2+}$ and $\mathrm{Cr}(\mathrm{VI})$ in potable water can provide better environmental remediation.
\end{abstract}

Keywords: Graphene oxide, N-rGO@TiO ${ }_{2}$, Nanocomposite, Cotton-seed, Heavy metals, Biodegradable, Sensing

\section{Introduction}

Over the past two decades, graphene-based materials are gaining tremendous attention from a scientific fraternity in various fields [1-3]. It may because of its astonishing properties and potential to revolutionize the scientific sector [3-5]. Graphene can be used to fabricate several dimension materials such as 1D nanostructure [6], 2D layer stacked films [7], 3D graphene hydrogel [7-9], and aerogel [10-13], etc. Out 
of various properties, graphene exhibited a high surface area in contrast to carbon nanotubes (CNTs) [14]. Also, it significantly enhances the electrochemical activity of various metal oxides such as titanium dioxide $\left(\mathrm{TiO}_{2}\right)$, zinc oxide ( $\mathrm{ZnO})$, etc). Several reports mentioned that the graphene in combination with photocatalysts resulted in the enhancement of the adsorption of pollutants [15-17]. Interestingly, several scientific groups are working on the conversion of graphene into a different unique form of graphene. On this account, the further modification of graphite (graphene) through oxidation gives the utmost graphene oxide (GO) [13, 18] and other structural models [13, 19-21]. Herein, GO exhibited abundant oxygen functionalities including carboxyl, epoxy and hydroxyl [22-24]. This GO containing oxygen functionalities, structural defects [25, 26] can be used for a range of applications. Further continuous development in GO leads to the synthesis of reduced GO (rGO). On this account, several methods have been reported for the rGO but they have some demerits such as influences of original electronic properties of graphene. Majorly reported methods can lead to ion doping and there is a chance of the presence of aggregate in nanocomposites. Besides, the uses of chemical reducing agents for the synthesis of rGO are hazardous, potentially explosive, and highly toxic to human health plus environments. Therefore, there is a need to stay away from the use of such toxic chemical agents. On this account, several eco-friendly green reducing agents (biomolecules, plant extracts and microbes) have been reported for the synthesis of rGO that acts as a capping agent and reducing agent [27]. Plenty of plant metabolites have been utilized for the fabrication of rGO for example plant extracts containing amino acids, vitamins, saccharides, microorganisms, proteins, etc. [28, 29]. Briefly, Zhang et al. reported vitamin $\mathrm{C}$ as a reductant for $\mathrm{GO}$ in combination with L-tryptophan [30]. Gou and coworkers confirmed that GO can be reduced using L-cysteine (amino acid) [31]. In a similar line, Dong et al. reported the synthesis of rGO using reducing sugar (fructose, glucose) [32]. Overall, these novel green synthesis approaches are based on several methods such as solvothermal, hydrothermal, electrochemical, microwave, and UV irradiation approaches [24]. It means the broader interest in green chemistry and environmentally sustainable synthesis of GO could be contributing to many new approaches for reducing GOs as excellent alternatives to traditional chemical processes.
From its inception, titanium dioxide $\left(\mathrm{TiO}_{2}\right)$ is extensively used in various pharmaceutical formulations such as toothpaste, ointments, paints and sunscreens. Furthermore, $\mathrm{TiO}_{2}$ has attracted significant attention in material chemistry and it has been well investigated by the research scholars. It may because of its strong redox ability, long-term stability against photo-corrosion and chemical corrosion, relative nontoxicity, and excellent optical plus electrical properties [27, 28, 33]. On the other hand, the photocatalytic potential of $\mathrm{TiO}_{2}$ is restricted owing to its low photocatalytic sensitivity in the UV region and the fast recombination of photogenerated electron-hole pairs [29, 31]. In this line, the photocatalytic performance of $\mathrm{TiO}_{2}$ can be increased by optimizing optical absorption and charge transfer characteristics. It is worth mentioning that the photocatalytic performance of $\mathrm{TiO}_{2}$ can be improved when combining with types of graphene-based nanocomposites [34-36].

In the last few years, several heteroatoms including boron (B), phosphorus (P), sulfur (S), and nitrogen $(\mathrm{N})$ have been successfully explored in sensing applications. The heteroatom doped nanocomposites lead to an improvement in overall required characteristics of novel synthesized material for sensing of different interest analyte [37, 38]. Among these above mentioned heteroatoms, the doping of $\mathrm{N}$ is of notable interest as of its electronrich nature, comparable size to that of carbon and high electronegativity of ' $N$ ', which might provide an appropriate location to fit into the graphene lattice. The finally obtained ' $\mathrm{N}$ ' doped graphene composites can be used for various applications [39-43]. In the line of doping-based sensing, the majority of investigations have been focused on N-doping only. Remarkably, it is well known to induce favorable changes like increasing conductivity into the carbon material $[38,44]$ and high activity in the redox reactions in fuel cells [45]. As per literature, the synthesis of $\mathrm{N}$-doped carbon material can be achieved through several pathways including post-treatment of carbon with ammonia [46], amines, or urea [47] and also it can be synthesized using more direct approaches using acetonitrile [48], pyrrol [49], polyacetonitrile $[2,50]$ as starting compounds.

As we know, the numbers of heavy metals naturally present in the environment that is in the normal range. unfortunately, during development in a different sector, the amount of heavy metals in nature is rising rapidly. it may due to various manufacturing and smelting activities. in addition to that, old infrastructure water 
sources, pollution from vehicles, polluted paint, different fertilizers, plastic, etc. are also helped to raise the level of heavy metals [51]. It is worth mentioning that most developed and under developing countries are suffering from issues of heavy metal pollution [52]. Nowadays, it becomes a major problem. in addition to that, presently we are suffering good quality water shortages due to water contamination. in this framework, the various pollutants including heavy metals are harmful to human beings plus the environment. it majorly affects the quality of the naturally available water. besides, because of the presence of such heavy metals, it causes many health issues such as gastrointestinal diseases, muscular diseases, tumors, reproductive diseases, neurological diseases, genetic disorders, etc [51]. therefore, there is a need to detect the level of heavy metals in potable water and separate it. numbers of research groups are working on the detection and separation of such water contaminants. nevertheless, most of the approaches are suffering from some hurdles such as sensitivity, selectivity. also, the chemically synthesized materials for sensing pollutants are limited its applications due to the use of toxic chemicals for the synthesis of such nanocomposites [51, 53-55].

In this attempt, we have synthesized N-rGO@ $\mathrm{TiO}_{2}$ nanocomposites for sensing heavy metal ions. Initially, we synthesized N-rGO@ $\mathrm{TiO}_{2}$ via fixing of $\mathrm{TiO}_{2}$ nanoparticles on GO sheets by a simple, green, eco-friendly, single-step method wherein cottonseeds extract is used as a green reducing agent. Finally, the spectroscopic detection of heavy metal ions from the potable water was investigated using stable N-rGO@ $\mathrm{TiO}_{2}$ nanocomposite. As a result, the N-rGO@TiO nanocomposites based spectroscopic detection of $\mathrm{Pb}^{2+}, \mathrm{Hg}^{2+}$, and $\mathrm{Cr}(\mathrm{VI})$ ions exhibited a good ability to detect these heavy metal ions in potable water efficiently. Taken as a whole, N-rGO@TiO ${ }_{2}$ could be a simple, rapid and economic method for heavy metal detection in water. In the future, our present work can encourage the $\mathrm{N}$-rGO@ $\mathrm{TiO}_{2}$ based future applications to remove $\mathrm{Pb}^{2+}, \mathrm{Hg}^{2+}$, and $\mathrm{Cr}(\mathrm{VI})$ ions from potable water.

\section{Experimental Materials}

Graphite flakes (particle size $8 \mu \mathrm{m}, 99.9995 \%$ ) were gifted by Asbury Carbons, New Jersey, USA. All of the chemicals utilized in this present work were of analytical grade and applied as received without further purification. Green source, cotton-seed was collected from the cotton processing center, Shirpur (MS), India.

\section{Synthesis of graphene oxide}

Initially, GO was synthesized using a modified Hummers method followed by slight modification [56]. In brief, sulfuric acid $\left(\mathrm{H}_{2} \mathrm{SO}_{4}\right)$ and phosphoric acid $\left(\mathrm{H}_{3} \mathrm{PO}_{4}\right)$ in the ratio of $27 \mathrm{~mL}: 3 \mathrm{~mL}$ were mixed properly followed by stirring for 15 min using a magnetic stirrer at $200 \mathrm{rpm}$. Subsequently, $0.225 \mathrm{~g}$ of graphite powder was added into the above mixture with constant stirring. After that, $1.32 \mathrm{~g}$ of potassium permanganate $\left(\mathrm{KMnO}_{4}\right)$ was added slowly into the previous graphite powder mixture followed by stirring up to 6 hrs until the color of the mixture became dark green. Then, hydrogen peroxide $\left(\mathrm{H}_{2} \mathrm{O}_{2}, 0.675 \mathrm{~mL}\right)$ was dropped slowly followed by stirring for $10 \mathrm{~min}$ to eliminate the excess of $\mathrm{KMnO}_{4}$. After completion of the reaction, the obtained mixture was cooled at room temperature. Furthermore, this mixture was purified three times by using hydrochloric acid ( $\mathrm{HCl})$ and DDW (1:3 ratio) and centrifuged using a cold centrifuge at $7000 \mathrm{rpm}$ (for $20 \mathrm{~min}$ at $25^{\circ} \mathrm{C}$ ). Finally, the obtained product was dried at $60^{\circ} \mathrm{C}$ for $24 \mathrm{~h}$.

\section{Synthesis of N-rGO@TiO,nano- composite}

Firstly, the following steps were implemented for the preparation of the $\mathrm{N}-\mathrm{rGO} @ \mathrm{TiO}_{2}$ nanocomposite. Initially, GO (75 mg) was dispersed into 10 $\mathrm{mL}$ of DDW followed by continuous stirring at room temperature (200 rpm). Then, sonication of nanocomposites was completed for $30 \mathrm{~min}$. After that, the collected cotton seed powder (50 mg) was added into $50 \mathrm{~mL}$ of DDW and refluxed for $1 \mathrm{~h}$. After that, the seed extract was filtered and further concentrated by centrifugation (7500 rpm for $30 \mathrm{~min}$ ) using a cold centrifuge (Refrigerated Centrifuge, Elteck Overseas Pvt., India). The obtained concentrated filtrate was used for further phytochemical testing and the nanocomposite synthesis process. Simultaneously, $\mathrm{TiO}_{2}$ dispersion was prepared by dispersing $50 \mathrm{mg} \mathrm{TiO}{ }_{2}$ into $10 \mathrm{~mL}$ DDW followed by sonication for $30 \mathrm{~min}$. After that, cotton seed extract $\mathrm{GO}$ and $\mathrm{TiO}_{2}$ dispersions were mixed (2:6:2) and heat on a water bath for $6 \mathrm{~h}\left(90^{\circ} \mathrm{C}\right)$. Consequently, the obtained composite was freeze-dried using a laboratory freeze dryer (Freezone12, Labconco, MO, USA). The N-rGO@ $\mathrm{TiO}_{2}$ composite was 
prefreezed at $-30{ }^{\circ} \mathrm{C}$ for $12 \mathrm{~h}$. After that, the primary drying of N-rGO@ $\mathrm{TiO}_{2}$ composites was performed at $-53{ }^{\circ} \mathrm{C}$ and 0.016 mbar for $24 \mathrm{~h}$. Then, the secondary drying of N-rGO@ $\mathrm{TiO}_{2}$ composites was performed at $10^{\circ} \mathrm{C}$ for $8 \mathrm{~h}$ followed by drying at $25^{\circ} \mathrm{C}$ for $4 \mathrm{~h}$ with a gradual increase in temperature at $1^{\circ} \mathrm{C} / \mathrm{min}$. Finally, the temperature of the cold trap was maintained at $-53{ }^{\circ} \mathrm{C}$ until the completion of the drying process. This resulted in N-rGO@ $\mathrm{TiO}_{2}$ composite powder was further used for subsequent evaluation studies.

\section{Characterization of N-rGO@ $\mathrm{TiO}_{2}$ nano- composite}

The synthesized GO and N-rGO@ $\mathrm{TiO}_{2}$ nanocomposite was characterized by various spectroscopic techniques. Initially, the UV-visible spectra of GO and nanocomposite were recorded between 800-400 $\mathrm{nm}$ through UV 1800 spectrophotometer (Shimadzu, Japan) using a quartz cuvette. The functional groups of GO and N-rGO@ $\mathrm{TiO}_{2}$ nanocomposites were examined using an IR spectrophotometer (DRS 8000 IR spectrophotometer Shimadzu 8400s, Japan) and scanned over a wave range of $4000-400 \mathrm{~cm}^{-1}$. The morphology and elemental analysis of GO and $\mathrm{N}$-rGO@ $\mathrm{TiO}_{2}$ nanocomposite were examined under a scanning electron microscope (SEM) with $15 \mathrm{kV}$ acceleration voltage and interpretation was carried out on Bruker, 1530-2 FESEM/EDX, Germany. The particle size analysis, as well as zeta potential of synthesized GO and N-rGO@ $\mathrm{TiO}_{2}$ nanocomposite, were measured using Nanoplus 3 Particulate System (Micromeritics, USA). Composite shape, size, were analyzed by using High-Resolution Transmission Electron Microscope (HR-TEM, Jeol/JEM 2100) using the LaB6 light source at $200 \mathrm{kV}$.

\section{Spectroscopic sensing of heavy metal ions by N-rGO@ $\mathrm{TiO}_{2}$ nanocomposite}

\section{Sensing of $\mathrm{Pb}^{2+}$ by $\mathrm{N}-\mathrm{rGO} @ \mathrm{TiO}_{2}$ nano- composites}

The selective detection of $\mathrm{Pb}^{2+}$ was performed by UV visible spectroscopic method. Typically, a stock solution of $1 \mathrm{mM}$ lead (II) chloride $\left(\mathrm{PbCl}_{2}\right)$ in water was prepared in DDW. After that, $1 \mathrm{~mL}$ of $10 \mathrm{nM}, 25$ $\mathrm{nM}, 50 \mathrm{nM}, 250 \mathrm{nM}, 500 \mathrm{nM}, 1000 \mathrm{nM}, 2500 \mathrm{nM}$, $5 \times 10^{3} \mathrm{nM}, 75 \times 10^{2} \mathrm{nM}$ and $1 \times 10^{4} \mathrm{nM}$ concentrations of $\mathrm{Pb}^{2+}$ were added into separate vials. Simultaneously, N-rGO@TiO 2 nanocomposite solution $(1 \mathrm{mg} / \mathrm{mL})$ was prepared in DDW. Then, $2 \mathrm{~mL}$ of $\mathrm{N}-\mathrm{rGO} @ \mathrm{TiO}_{2}$ nanocomposite solution was added above different test tubes. Similarly, the real-time sensing of the $\mathrm{Pb}^{2+}$ in spiked sample was performed using N-rGO@ $\mathrm{TiO}_{2}$ nanocomposites. In that, $100 \mathrm{nM}$ concentration of $\mathrm{Pb}^{2+}$ was added into vials containing 2 mL of N-rGO@ $\mathrm{TiO}_{2}$ nanocomposite. After thorough shaking, the color change in the test tube solution was observed by the naked eye followed by a recording of UV-Vis absorption spectra from 800-200 nm.

\section{Sensing of $\mathrm{Hg}^{2+}$ by N-rGO@TiO ${ }_{2}$ nano- composites}

The absorption spectra of the N-rGO@ $\mathrm{TiO}_{2}$ nanocomposite were recorded by adding different concentrations of $\mathrm{Hg}^{2+}$. In brief, the different concentration $(10 \mu \mathrm{M}, 15 \mu \mathrm{M}, 50 \mu \mathrm{M}, 100 \mu \mathrm{M}, 250$ $\mu \mathrm{M}, 500 \mu \mathrm{M}, 1000 \mu \mathrm{M})$ of $\mathrm{HgCl}_{2}$ were prepared. Then, $1 \mathrm{~mL}$ of this solution was added into $2 \mathrm{~mL}$ of N-rGO@ $\mathrm{TiO}_{2}$ nanocomposite solution followed by shaking and subjected to $2 \mathrm{~min}$ as a resting time. The changes in the N-rGO@ $\mathrm{TiO}_{2}$ nanocomposite absorbance band with the addition of diverse concentrations of $\mathrm{Hg}^{2+}$ were monitored by recording absorption spectra from $800 \mathrm{~nm}-200 \mathrm{~nm}$. For detection, the different $\mathrm{Hg}^{2+}$ concentrations were added separately into the N-rGO@ $\mathrm{TiO}_{2}$ nanocomposite solution followed by mixing and allowed to rest. Finally, real-time sensing of $\mathrm{Hg}^{2+}$ was performed in a spiked sample using N-rGO@ $@ \mathrm{TiO}_{2}$ nanocomposites. In that, $75 \mu \mathrm{M}$ concentration of $\mathrm{Hg}^{2+}$ was added into vials containing 2mL of N-rGO@ $\mathrm{TiO}_{2}$ nanocomposite. The color changes in vials were observed with the naked eye followed by a recording of UV-Vis absorption spectra from $800-200 \mathrm{~nm}$.

\section{Sensing of $\mathrm{Cr}$ (VI) by N-rGO@TiO ${ }_{2}$ nano- composites}

The detection of $\mathrm{Cr}$ (VI) was performed using $\mathrm{N}-\mathrm{rGO} @ \mathrm{TiO}_{2}$ through UV visible spectroscopic method. Firstly, the stock solution of $1 \mathrm{mM} \mathrm{K}_{2} \mathrm{Cr}_{2} \mathrm{O}_{7}$ was prepared in DDW. Simultaneously, N-rGO@TiO nanocomposites solution $(1 \mathrm{mg} / \mathrm{mL})$ was prepared in DDW. Herein, $1 \mathrm{~mL}$ of $10 \mathrm{nM}, 25 \mathrm{nM}, 50 \mathrm{nM}, 250$ $\mathrm{nM}, 500 \mathrm{nM}, 2500 \mathrm{nM}, 5 \times 10^{3} \mathrm{nM}, 75 \times 10^{2} \mathrm{nM}$, and $1 \times 10^{4} \mathrm{nM}$ were added in separate vials. Then, $2 \mathrm{~mL}$ of $\mathrm{N}-\mathrm{rGO} @ \mathrm{TiO}_{2}$ nanocomposites solution was added into previously prepared vials. Real-time sensing of $\mathrm{Cr}(\mathrm{VI})$ in a spiked sample was performed using N-rGO@ $\mathrm{TiO}_{2}$ nanocomposites. In that, $50 \mathrm{nM}$ concentration of $\mathrm{Cr}$ (VI) was added into vials containing 2 mL of N-rGO@ $\mathrm{TiO}_{2}$ nanocomposite. After thorough shaking, the color changes in the solution were observed by recoding UVVis absorption spectra from $800-200 \mathrm{~nm}$. 


\section{Results and Discussion}

The phytoconstituents screening of cotton-seed extract was showed the presence of carbohydrates, proteins, amino acids, tannins, phenols, alkaloids, and flavonoids, etc [57]. Due to the presence of phytoconstituents, the green synthesis of rGO-based nanocomposites can be possible [58].

\section{UV-vis absorption study}

The UV absorption spectra of GO and N-rGO@ $\mathrm{TiO}_{2}$ nanocomposite are depicted in Fig. 1. In brief, Figure $1 \mathrm{~A}$ demonstrates that the GO dispersion exhibited an intense absorption peak at $232 \mathrm{~nm}\left(\lambda_{\max }\right)$ which corresponds to $\pi-\pi^{*}$ transitions of an aromatic ring containing $\mathrm{C}-\mathrm{C}$ bonds and slightly low intense shoulder peak at $300 \mathrm{~nm}$ due to graphene, $n-\pi$ transitions of C-O bonds, respectively. Based on this, it confirmed the synthesis of GO. The UV Visible spectrum was conducted to investigate the optical absorption capability of the N-rGO@ $\mathrm{TiO}_{2}$ nanocomposite, as shown in Fig. 1. The $\mathrm{TiO}_{2}$ dispersion exhibited the characteristic absorption at around $350 \mathrm{~nm}$ in the UV region. However, a gradual red-shift to longer wavelengths was observed for the N-rGO@TiO nanocomposite fabricated using the one-pot method. The red-shift absorption was attributed due to the construction of the Ti-O-C bond, which reduces the band-gap energy of the N-rGO@TiO ${ }_{2}$ nanocomposites. On the other hand, it gets hybridized with $\mathrm{O} 2 \mathrm{p}$ and $\mathrm{C}$ $2 \mathrm{p}$ atomic orbital under high pressure and temperature. Also, the introduction of ' $\mathrm{N}$ ' into the graphene nanosheet resulted in the high absorption intensity

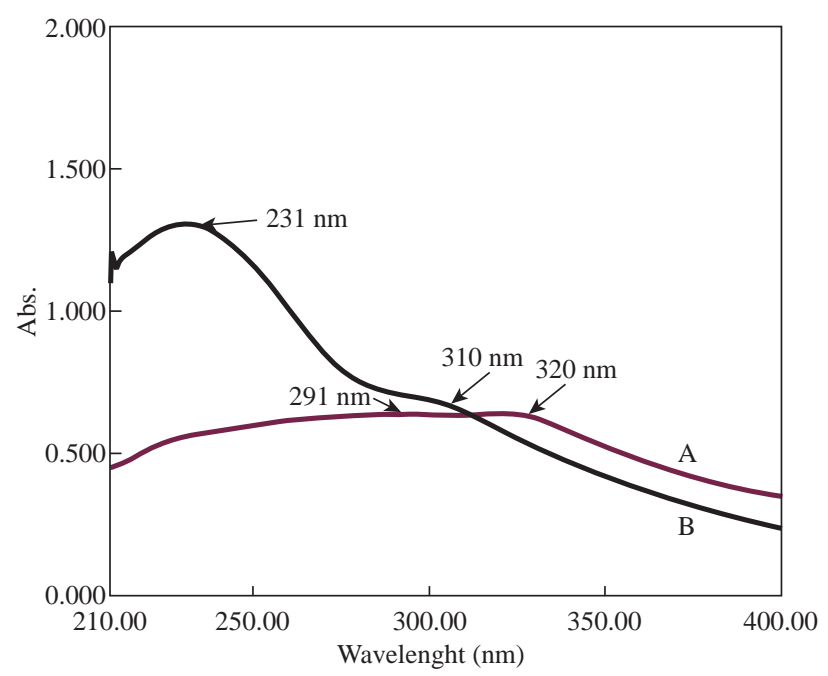

Fig. 1 UV visible spectra of (a) GO and (b) N-rGO@ $\mathrm{TiO}_{2}$ nanocomposite. as compared to the plain $\mathrm{TiO}_{2}$ [59]. So, it confirmed that the shift in the absorption in the UV-Vis range of $\mathrm{N}-\mathrm{rGO} @ \mathrm{TiO}_{2}$ is due to N-doping.

\section{FTIR analysis}

FTIR analysis GO and N-rGO@TiO 2 are depicted in Fig. 2. Figure 2A shows a broad-band around $3300 \mathrm{~cm}^{-1}$ that confirmed the stretching vibrations of $\mathrm{O}-\mathrm{H}$ groups in GO. The various prominent vibrational bands $\left(\mathrm{cm}^{-1}\right)$ for GO were observed at $\sim 2900 \mathrm{~cm}^{-1}, 2800 \mathrm{~cm}^{-1}, 1730 \mathrm{~cm}^{-1}$, $1400 \mathrm{~cm}^{-1}, 1200 \mathrm{~cm}^{-1}$, and $1030 \mathrm{~cm}^{-1}$, which have been assigned to symmetrical $\mathrm{C}-\mathrm{H}$ stretching, unsymmetrical $\mathrm{C}-\mathrm{H}$ stretching, $\mathrm{C}=\mathrm{O}$ stretching, $\mathrm{O}-\mathrm{H}$ bending, $\mathrm{C}-\mathrm{O}-\mathrm{C}$ stretching and $\mathrm{C}-\mathrm{O}$ stretching, respectively [60]. Therefore, we conclude that the flourishing synthesis of GO. Figure 2B confirmed that the FTIR spectrum of N-rGO@ $\mathrm{TiO}_{2}$ nanocomposite shows a band at 3561 $\mathrm{cm}^{-1}, 3120 \mathrm{~cm}^{-1}, 2947 \mathrm{~cm}^{-1}$ that confirmed the $\mathrm{N}-\mathrm{H}$ stretching vibrations, O-H stretching, C-H stretching, respectively. Furthermore, the peaks at $1670 \mathrm{~cm}^{-1}$ and $1556 \mathrm{~cm}^{-1}$ which are correspond to the $\mathrm{C}=\mathrm{N}$ and $\mathrm{C}=\mathrm{O}$ stretching and vibration mode. The peak corresponds to $\mathrm{C}=\mathrm{O}$ stretching, vibration in $\mathrm{GO}$ was decreased due to the reduction of oxygen functionalities. The peak at $1228 \mathrm{~cm}^{-1}$ and $1041 \mathrm{~cm}^{-1}$ was observed due to $\mathrm{C}-\mathrm{O}$ stretching vibration. Two peaks were also observed for Ti-O-C and Ti-O-Ti at $673 \mathrm{~cm}^{-1}$ and 497 $\mathrm{cm}^{-1}$, respectively [61]. It may due to the interaction of $\mathrm{TiO}_{2}$ with rGO sheets. Therefore, based on the FTIR, we conclude that the synthesis of N-rGO@ $\mathrm{TiO}_{2}$ nanocomposite. Herein, FTIR spectra of GO confirmed that the presence of oxygen functionalities such as $\mathrm{COOH},-\mathrm{OH}$, etc. when $\mathrm{TiO}_{2}$ nanoparticles mixed with GO, the nanoparticle get fixed on the surface of the GO sheet due to the bonding between $\mathrm{TiO}_{2}$ and GO that form the new bonds such as -COO-. After

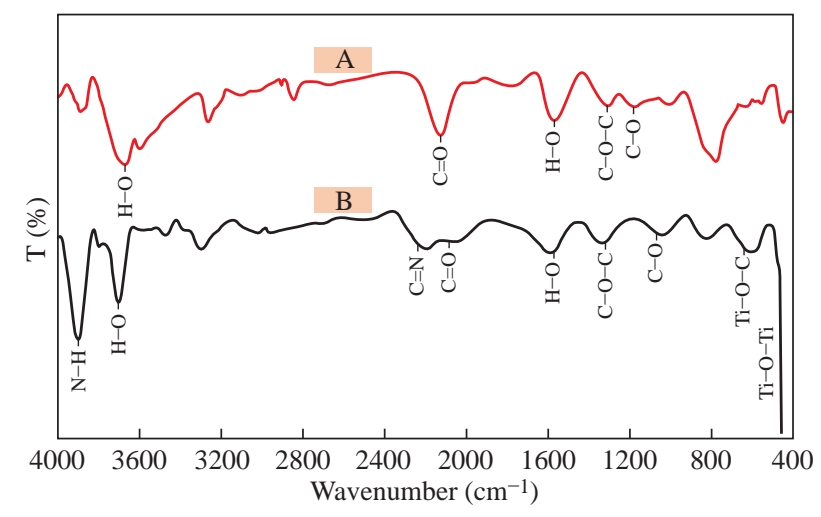

Fig. 2 IR spectra of (a) GO and (b) N-rGO@ $\mathrm{TiO}_{2}$ nanocomposites. 
the successful reduction of GO in nanocomposites, the free nanoparticles are entrapped into the $3 \mathrm{D}$ structure of nanocomposites via physical entrapment. Finally, it gives the 3D self assemble nanosized, stable hydrogel [62].

\section{Scanning electron microscopy and high-resolution transmission electron microscopy}

Generally, the SEM is used to confirm the surface morphology of materials. Based on this, it facilitates the verification of synthesis of nanocomposites. Herein, Figure 3(a) and Figure 3(b) shows a wrinkled and typical crumpled surface. Also, the sheets are stacked together and form a typical multi-layer structure of GO. Normally, the wrinkled arrangement of GO sheets offers a great rough surface. Besides, due to such unique nature of GO sheets, it offers more surface for doping of heteroatoms [61]. Figure 3(c) and Figure 3(d) show the SEM images of the N-rGO@ $\mathrm{TiO}_{2}$ nanocomposite that confirms the surface morphological microstructures of the N-rGO@ $\mathrm{TiO}_{2}$ nanocomposite. As per Figure $1 \mathrm{~A}$ and $\mathrm{B}$, the GO sheets show wrinkled and folded form, whereas nanocomposites showed cross-linking of $\mathrm{TiO}_{2}$ nanoparticles on the surface of the GO sheet that formed the network structures in $\mathrm{N}-\mathrm{rGO} @ \mathrm{TiO}_{2}$ nanocomposite. The HR-TEM image of the N-rGO@ $\mathrm{TiO}_{2}$ nanocomposite is shown in Fig. 3(e). The TEM analysis demonstrates that the spherical shapes $\mathrm{TiO}_{2}$ nanoparticles are distributed and attached on the surface of the rGO sheet. The size distribution of $\mathrm{TiO}_{2}$ nanoparticles in N-rGO@ $\mathrm{TiO}_{2}$ nanocomposite was found to be $42 \mathrm{~nm}$ to 115 $\mathrm{nm}$. Besides this, the anchoring of $\mathrm{TiO}_{2}$ was found on the sheet of the rGO, it might because of the chemical bonding and physical entrapment of nanoparticles into the mixture of graphene. The morphology of ' $\mathrm{N}$ ' doped nanocomposite showed the stacked layer of graphene thin layers that resulted in the multilayered graphene nanosheet. Notably, the curled edge and fold appearance in nanocomposite was credited to the defect structure, which may be caused due to the ' $N$ ' doped graphene sheet [59]. Overall, the SEM and HRTEM images confirmed the rough surface of the N-rGO@ $\mathrm{TiO}_{2}$ nanocomposite. It may because of the attachment of $\mathrm{TiO}_{2}$ nanoparticles on the stable dispersion of the nanosized rGO sheet. The formation of nanocomposites meant that the restored conjugated arrangement of GO sheets reduces and functionalized using CSE in an aqueous medium. Overall, it indicates partial overlapping and aggregation of flexible GO sheets via $\pi-\pi$ stacking interaction resulted in $3 \mathrm{D}$ graphene porous network. During the synthesis of the nanocomposite, the GO containing oxygen functional groups might be notably reduced during synthesis process. Interestingly, the $\pi-\pi$ intrinsic interaction between rGO is slowly restored in nanocomposites. Furthermore, the slight overlapping and coalescing of flexible nanosized rGO converted into the $3 \mathrm{D}$ porous nanostructure. During the synthesis of the composite, the nanoparticle completely decorates the rGO
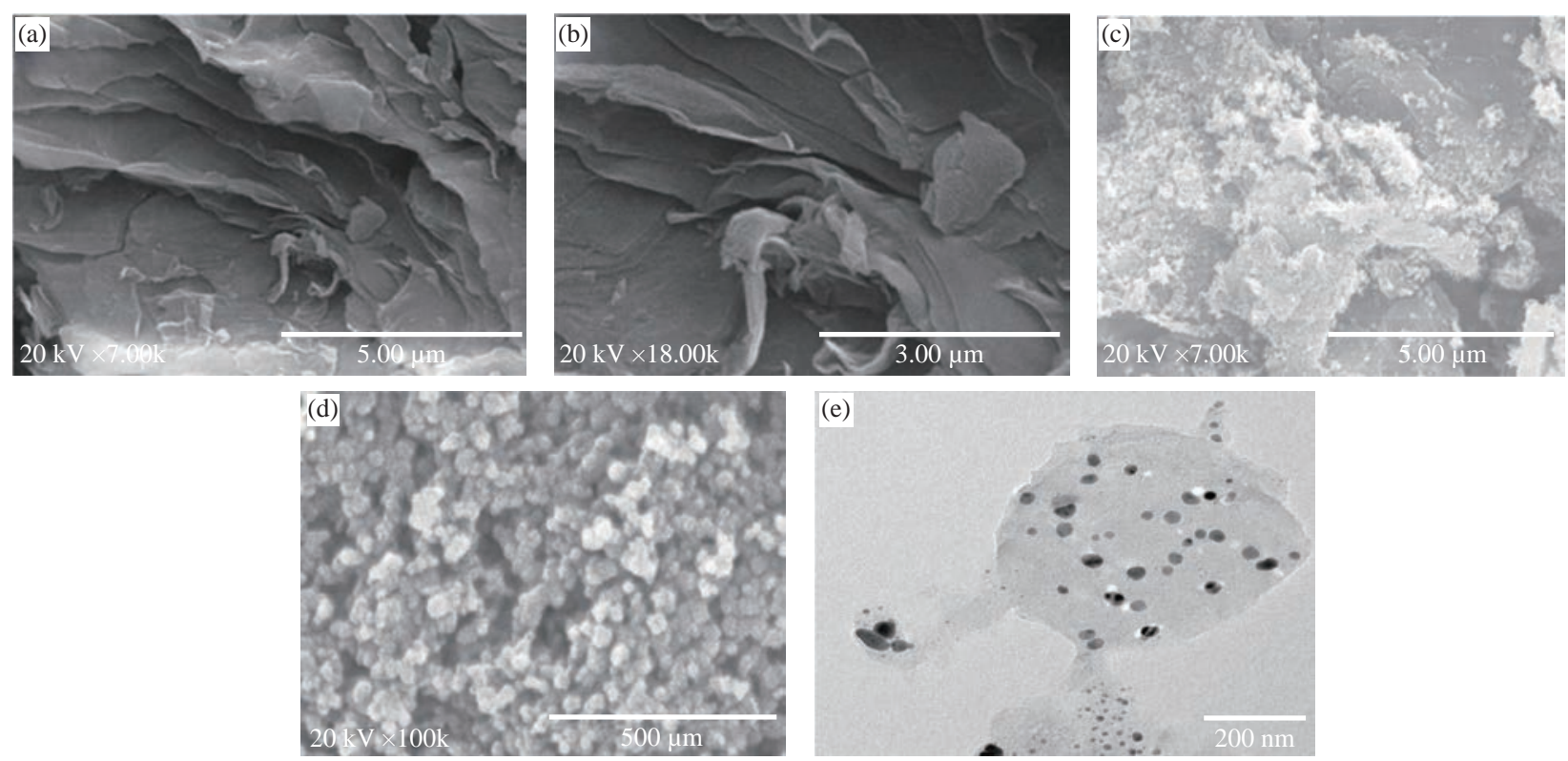

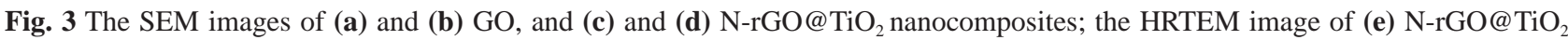
nanocomposite. 
sheets. It helps to avoid the aggregations of graphene nanosheets. Automatically, it improves the volume and surface areas of nanocomposites. Fascinatingly, $\mathrm{TiO}_{2}$ nanoparticles also provide the bridge to connect the RGO nanosheets via chemical bonding, and finally, it is converted into the pores with smaller size. Simultaneously, $\pi-\pi$ intrinsic conjugation gets weakened in rGO and it provides a high quantity of $\mathrm{TiO}_{2}$ anchoring on the surface of 3D graphene sheet [63].

\section{Elemental analysis by EDAX}

The elemental composition of nanocomposites plays an important role for to achieve the highly sensitive detection of the analyte. In this context, the EDAX provides the details of elements present in the composition. In this report, Figure 4(a) demonstrates the EDX spectra of GO, which confirmed the presence of carbon (C) and oxygen (O) at about $34.31 \mathrm{wt} \%$ and $64.69 \mathrm{wt} \%$, respectively. As per literature, the presence of ' $\mathrm{O}$ ' confirmed the different ' $\mathrm{O}$ ' functionalities are present on the surface of the GO sheet. It provides the bonding among different metal ions, which helps to sense the interest analyte. Besides, it also acts as an intermediate for nanocomposite synthesis. The doping of ' $\mathrm{N}$ ' in nanocomposite can confirm based on the percent composition of ' $\mathrm{N}$ ' present in the final formulation. In this report, Figure 4(b) provides the EDAX spectrum of N-rGO@ $\mathrm{TiO}_{2}$ nanocomposites. In brief, EDAX spectra of N-rGO@ $\mathrm{TiO}_{2}$ confirmed that the $1.45 \mathrm{wt} \%$ of ' $\mathrm{N}$ ' and $43.77 \mathrm{wt} \%$ of ' $\mathrm{C}$ ' were present in the nanocomposite. The analysis of EDAX spectra showed a significant decrease in ' $\mathrm{O}$ ' about 38 $\mathrm{wt} \%$. It may due to the doping of ' $\mathrm{N}$ ' on the GO sheets. Furthermore, the content of ' $\mathrm{Ti}$ ' was found to be 16.78 wt $\%$. Therefore, based on the existing elements such as $\mathrm{N}, \mathrm{C}, \mathrm{O}, \mathrm{Ti}$, confirmed the complete formation of $\mathrm{N}-\mathrm{rGO} @ \mathrm{TiO}_{2}$ nanocomposite.

\section{Particle size and zeta potential analysis}

Particle size analysis is performed to confirm the distribution (or average diameters) of nanomaterials, whereas zeta potential provides the information about the stability of nanocomposite. Figure 5(a) demonstrates the particle size distribution of synthesized GO. Herein, the average diameter of GO was found to be $81.2 \mathrm{~nm}$ (Figure 5(a)). The polydispersity index of GO dispersion was found to 0.42 , which confirmed the uniform distribution of GO nanosized sheets in dispersion. The zeta potential
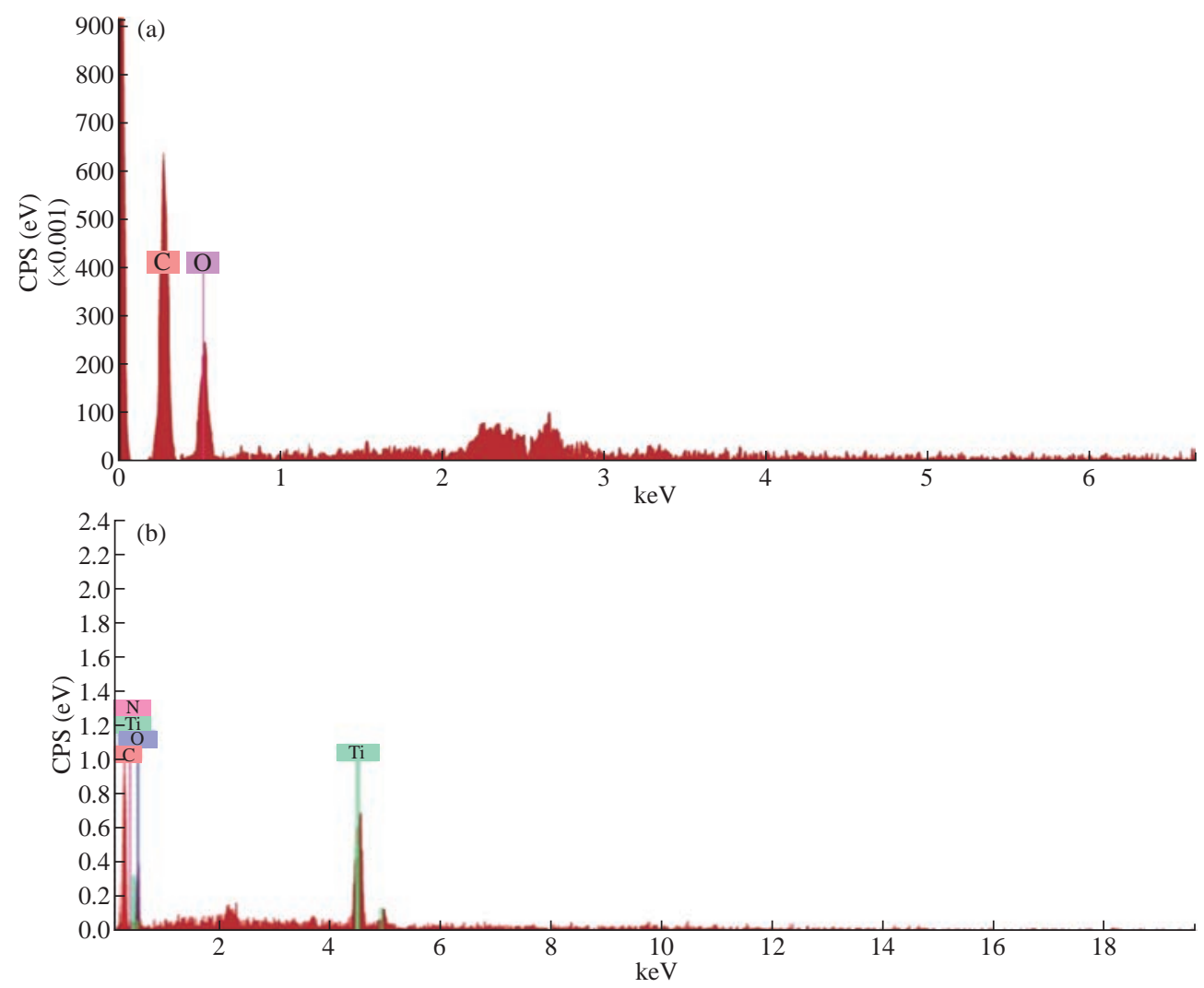

Fig. 4 EDX spectra of (a) GO and (b) N-rGO@ $\mathrm{TiO}_{2}$ nanocomposites. 

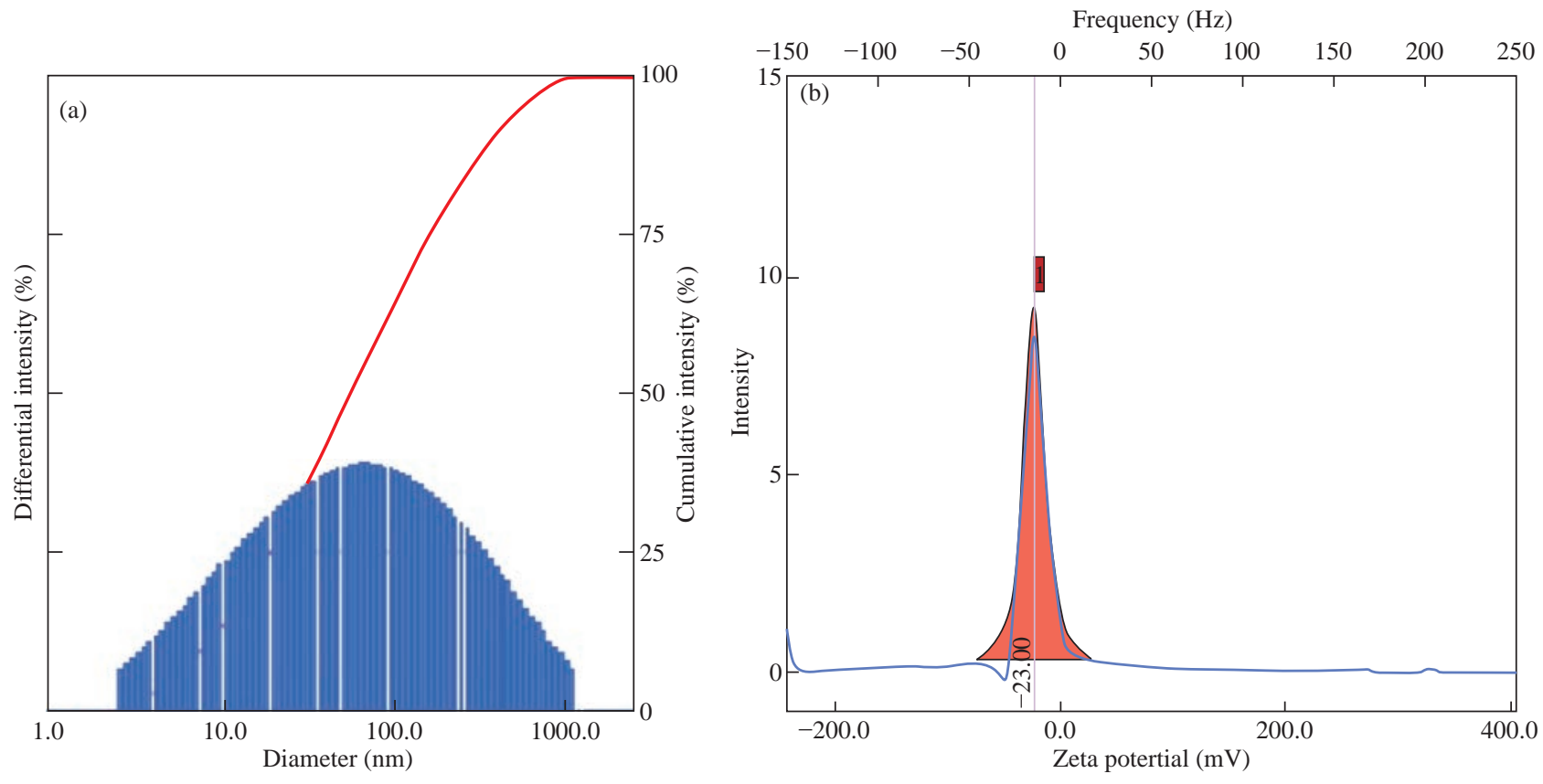

Fig. 5 (a) Particle size and (b) zeta potential of GO.

analysis of GO dispersion was found to be $-23.00 \mathrm{mV}$ (Figure 5(b)). Therefore, it confirmed the uniform distribution and stability of nanosized GO sheets in dispersion. Figure 6(a) provides the particle size distribution of the N-rGO@ $\mathrm{TiO}_{2}$ nanocomposite. The average particle size of the N-rGO@TiO nanocomposite was found to be $357.6 \mathrm{~nm}$ that assured the synthesis of the $\mathrm{N}$ doped nanosized composite. The polydispersity index of nanocomposite was found to be 0.51 that confirmed the uniform distribution of nanocomposite in water. The zeta potential analysis of $\mathrm{N}$-rGO@ $\mathrm{TiO}_{2}$ is depicted in Fig. 6(b). The nanosized composites showed a positive zeta potential of about $+29.55 \mathrm{mV}$, which confirmed the stability of the nanocomposite and successful doping of $\mathrm{N}$ into the rGO sheet. Overall, based on these findings, it confirmed that the N-rGO@ $\mathrm{TiO}_{2}$ composite exhibited the nanosized distribution and high stability in dispersion.

\section{Spectroscopic sensing of $\mathrm{Pb}^{2+}, \mathrm{Hg}^{2+}$, and Cr (VI) by N-rGO@TiO nanocomposites}

In this study, the synthesized N-rGO@ $\mathrm{TiO}_{2}$ nanocomposite was checked for the spectral as well as optical detection of the above mentioned heavy metal
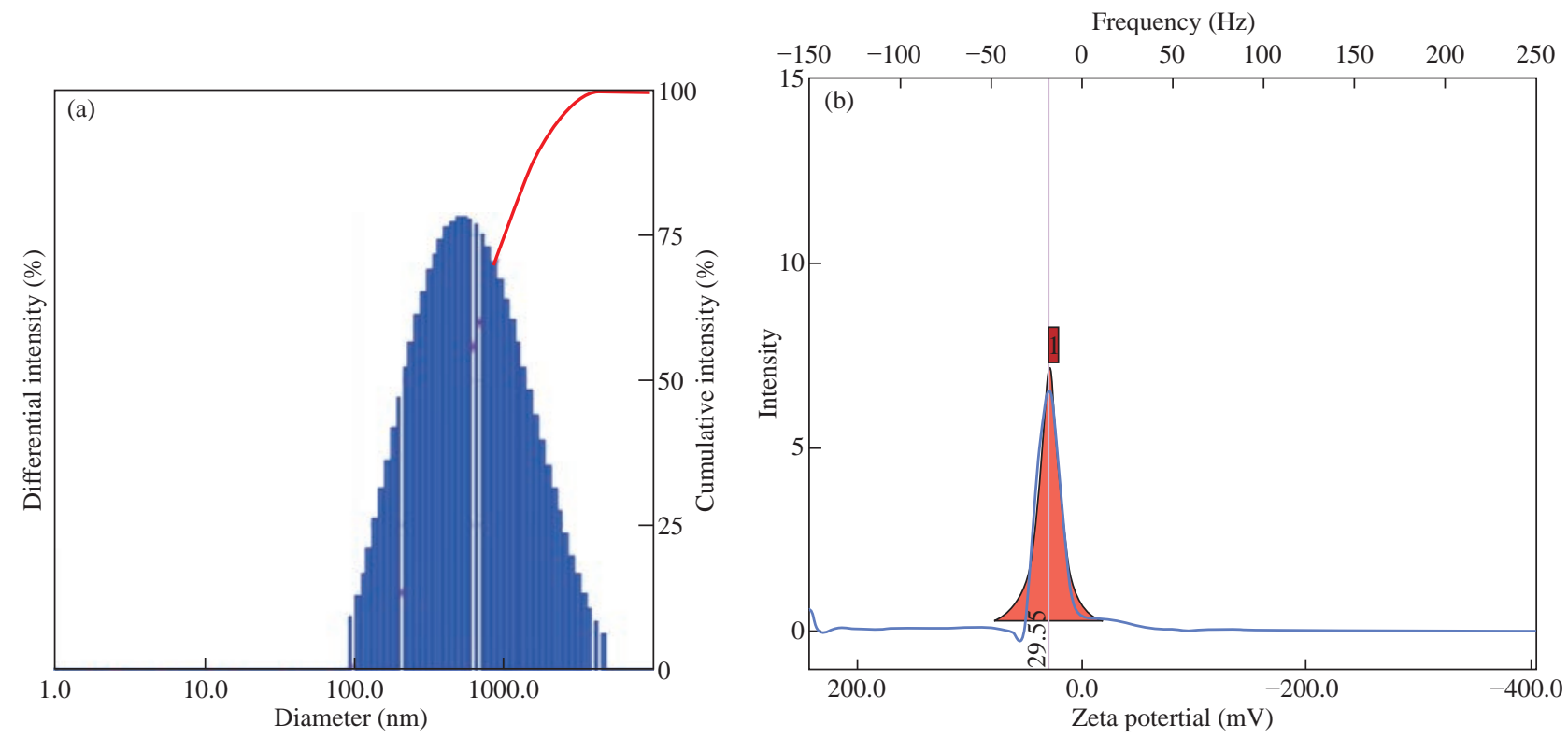

Fig. 6 (a) Particle size and (b) zeta potential of N-rGO@ $\mathrm{TiO}_{2}$ nanocomposite. 
ions. The details of the sensing study are discussed in the respective subsection.

\section{Sensing of $\mathrm{Pb}^{2+}$}

The synthesized N-rGO@ $\mathrm{TiO}_{2}$ nanocomposite was tested for the spectral and optical detection of $\mathrm{Pb}^{2+}$ ions. In brief, the detection of $\mathrm{Pb}^{2+}$ ions by $\mathrm{N}-\mathrm{rGO} @ \mathrm{TiO}_{2}$ nanocomposite revealed that the UVvisible spectra absorption peaks decreased with an increasing concentration of $\mathrm{Pb}^{2+}$ ions are shown in Fig. 7. The changes in the UV spectra of the N-rGO@ $\mathrm{TiO}_{2}$ nanocomposite solution help to calculate the $\mathrm{nM}$ concentration of $\mathrm{Pb}^{2+}$ ions $\left(r^{2}=0.0074 \mathrm{x}+0.08\right)$. In this study, nanocomposites intensity dramatically decreased with an increasing amount of $\mathrm{Pb}^{2+}$ ions. The sudden change was observed at $50 \mathrm{nM}$ concentration. Therefore, the detection limit of $\mathrm{Pb}^{2+}$ was found to be $50 \mathrm{nM}$. After the addition of $1 \times 10^{4} \mathrm{nM}$ concentration of $\mathrm{Pb}^{2+}$ ions into the N-rGO@ $\mathrm{TiO}_{2}$ composite solution, the characteristic peak completely disappeared. It may due to the loss of characteristic properties of nanoregion after the strong aggregation of N-rGO@ $\mathrm{TiO}_{2}$ aerogel at this high concentration of $\mathrm{Pb}^{2+}$. The spiked sample analysis was showed the $100 \mathrm{nM}$ concentration of $\mathrm{Pb}^{2+}$ in the waste-water. Overall, upon addition of $\mathrm{Pb}^{2+}$ ions in the N-rGO@TiO ${ }_{2}$ solution turned colorless that induced by aggregation of N-rGO@ $\mathrm{TiO}_{2}$ aerogel, which was detected visually and also confirmed by UV spectroscopy.

\section{Sensing of $\mathrm{Hg}^{2+}$}

The N-rGO@ $\mathrm{TiO}_{2}$ nanocomposite was tested for the spectroscopic determination of $\mathrm{Hg}^{2+}$. Because

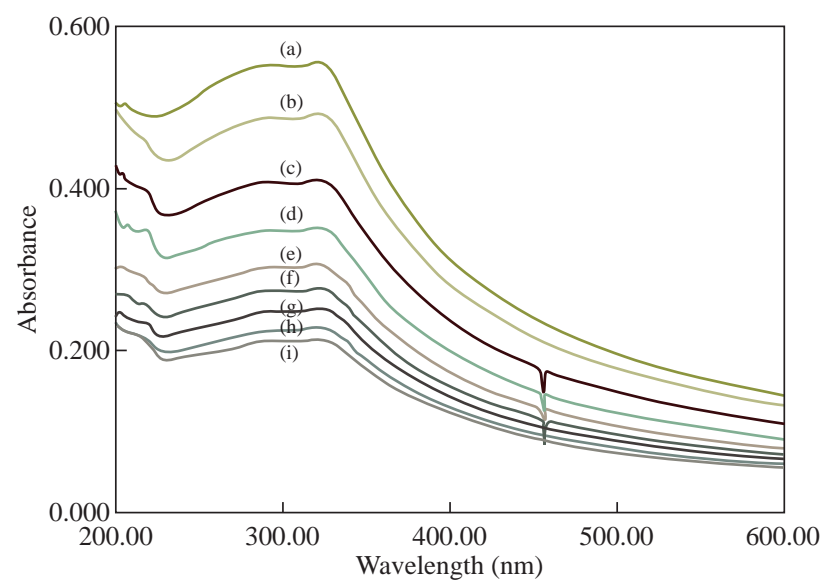

Fig. 7 Spectroscopic sensing of $\mathrm{Pb}^{2+}$ by N-rGO@ $\mathrm{TiO}_{2}$ nanocomposite: (a) $0 \mathrm{nM}$, (b) $50 \mathrm{nM}$, (c) spiked sample (100 $\mathrm{nM}$ ), (d) $250 \mathrm{nM}$, (e) $500 \mathrm{nM}$, (f) $1000 \mathrm{nM}$, (g) $2500 \mathrm{nM}$, (h) $5 \times 10^{3} \mathrm{nM}$, and (i) $75 \times 10^{2} \mathrm{nM}$ of $\mathrm{PbCl}_{2}$ with N-rGO@ $\mathrm{TiO}_{2}$ nanocomposite. of the formation of an intense UV absorption band of N-rGO@ $\mathrm{TiO}_{2}$ nanocomposite, it is much straightforward to monitor changes in the UV absorption band during the determination of $\mathrm{Hg}^{2+}$ (Fig. 8). A significant decrease in the absorption peak with a red-shift on the UV band of the N-rGO@ $\mathrm{TiO}_{2}$ nanocomposite was observed upon increasing the concentration of $\mathrm{Hg}^{2+}$ ions. Thus, the $\mathrm{Hg}^{2+}$ with a concentration of $15 \mu \mathrm{M}$ was taken as a limit of detection for N-rGO@ $\mathrm{TiO}_{2}$ nanocomposite $\left(r^{2}=0.022 \mathrm{x}\right.$ $+0.09)$. After the addition of $1000 \mu \mathrm{M}$ concentration of $\mathrm{Hg}^{2+}$ into the nanocomposite, the UV absorption peak was completely disappeared. The spiked sample analysis confirmed the presence of $75 \mu \mathrm{M} \mathrm{Hg}^{2+}$ ions in the wastewater. The red-shift and significant decrease in the absorption peak intensity were caused due to the redox interaction between the $\mathrm{Hg}^{2+}$ ions and the N-rGO@TiO ${ }_{2}$ nanocomposite. The red-shift in the UV absorption band can be attributed to the adsorption of $\mathrm{Hg}^{2+}$ onto the N-rGO@ $\mathrm{TiO}_{2}$ nanocomposite surface and thereby formed a combination. Finally, the addition of $\mathrm{Hg}^{2+}$, N-rGO@ $\mathrm{TiO}_{2}$ nanocomposite was turned colorless.

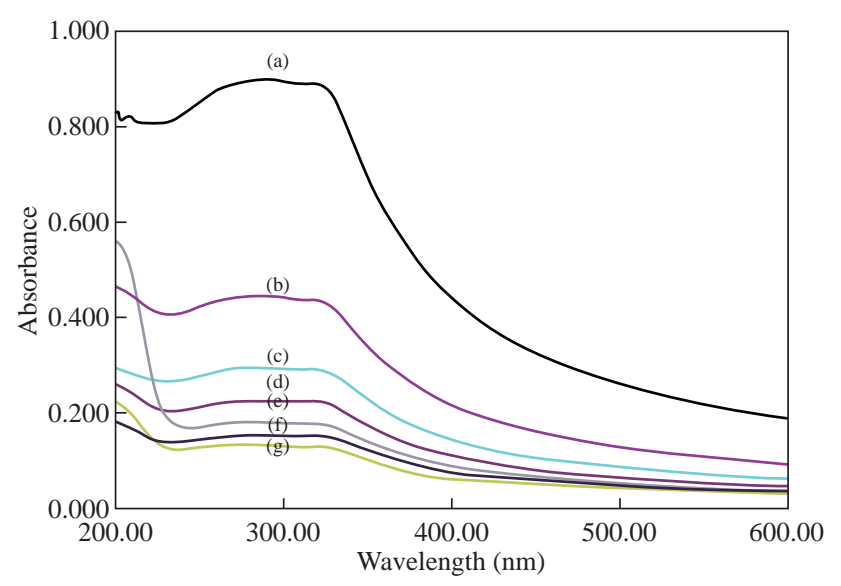

Fig. 8 UV absorption spectral changes observed for N-rGO@ $\mathrm{TiO}_{2}$ nanocomposite upon the addition of $\mathrm{Hg}^{2+}$ ions: (a) $0 \mu \mathrm{M}$, (b) $15 \mu \mathrm{M}$, (c) $50 \mu \mathrm{M}$, (d) $75 \mu \mathrm{M}$, (e) $100 \mu \mathrm{M}$, (f) $250 \mu \mathrm{M}$, and (g) $500 \mu \mathrm{M}$ of $\mathrm{Hg}^{2+}$ ions with $\mathrm{N}-\mathrm{rGO} @ \mathrm{TiO}_{2}$ nanocomposite.

\section{Sensing of $\mathrm{Cr}(\mathrm{VI})$}

The detection of Cr (VI) ion by the N-rGO@ $\mathrm{TiO}_{2}$ nanocomposite was performed by the UV spectroscopically. Figure 9 shows the UV absorption spectra of $\mathrm{N}-\mathrm{rGO} @ \mathrm{TiO}_{2}$ nanocomposite get increased with a decreased the concentration of $\mathrm{Cr}$ (VI) ions. It means the intensity of the UV absorption peak of the $\mathrm{N}-\mathrm{rGO} @ \mathrm{TiO}_{2}$ nanocomposite is inversely proportional to the concentration of $\mathrm{Cr}$ (VI). Finally, the peak that disappeared was at the highest concentration of $\mathrm{Cr}$ 


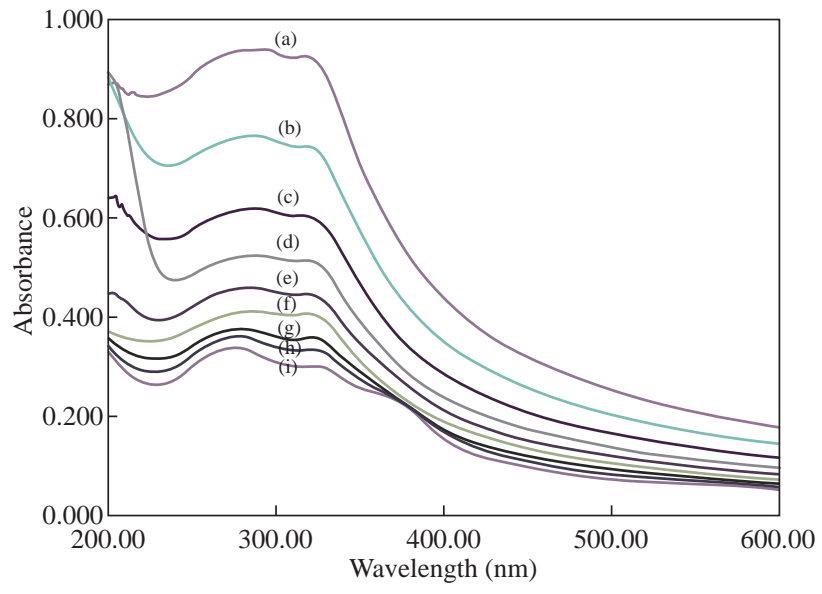

Fig. 9 Spectroscopic sensing of $\mathrm{Cr}(\mathrm{VI})$ using N-rGO@ $\mathrm{TiO}_{2}$ nanocomposites: (a) $0 \mathrm{nM}$, (b) $25 \mathrm{nM}$, (c) spiked sample (50 nM), (d) $100 \mathrm{nM}$, (e) $250 \mathrm{nM}$, (f) $500 \mathrm{nM}$, (g) $2500 \mathrm{nM}$, (h) $5 \times 10^{3} \mathrm{nM}$, and (i) $75 \times 10^{2} \mathrm{nM}$ of $\mathrm{K}_{2} \mathrm{Cr}_{2} \mathrm{O}_{7}$ solution with $\mathrm{N}-\mathrm{rGO} @$ $\mathrm{TiO}_{2}$ nanocomposite.

(VI) ions. The change in the UV spectra of N-rGO@ $\mathrm{TiO}_{2}$ nanocomposite occurs at $25 \mathrm{nM}$ concentration of $\mathrm{Cr}$ (VI) ions. It exhibited a prominent peak at $283 \mathrm{~nm}$ $\left(r^{2}=0.0014 \mathrm{x}+0.05\right)$. The intensity of this peak was significantly decreased with increasing concentration of $\mathrm{Cr}$ (VI). The sudden changes of the peak at $25 \mathrm{nM}$ concentration of $\mathrm{Cr}$ (VI) were considered as a limit of detection. After the addition of $1 \times 10^{4} \mathrm{nM}$ concentration of $\mathrm{Cr}$ (VI) ions into the N-rGO@TiO ${ }_{2}$ nanocomposite solution, the characteristic UV absorption peak was completely disappeared. The spiked sample analysis showed the $50 \mathrm{nM}$ concentration of $\mathrm{Cr}$ (VI) was present in the wastewater. Overall, due to the strong adsorption of $\mathrm{Cr}(\mathrm{VI})$ on the N-rGO@ $\mathrm{TiO}_{2}$ nanocomposite, it provides excellent sensing ability. Finally, the addition of $\mathrm{Cr}$ (VI) ion in the solution of

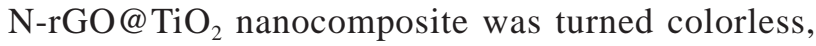
which can be determined visually and can be confirmed by UV spectroscopy.

As per the literature, the addition of $\mathrm{TiO}_{2}$ nanoparticles in graphene-based materials enhances the catalytic activity of nanoparticles. It may due to the high surface area and electron mobility of graphene. Moreover, it showed a high affinity towards the interest analyte. In addition, it provides a higher charge separation as well as higher charge transport potential. The main sensing mechanism of this nanocomposite is still unknown, but several possible mechanisms have been reported by previously published literature. In brief, the addition of rGO helps to the adsorption of heavy metals on the surface of nanocomposites via strong electrostatic interaction plus $\pi$ - $\pi$ stacking. Concisely, the graphene-based nanocomposite containing $\pi$ domains is the major part of the driving force to the sensing of heavy metal ions. Furthermore, the synthesized nanocomposites were in 3D form. Owing to the 3D structure, it offers a high surface area and a more porous nature as compared to the $2 \mathrm{D}$ materials. It may provide the higher binding sites for sensing of heavy metals [63]. Notable, the $\mathrm{N}$ contains the same atomic radius as graphene containing carbon. Due to the same atomic radius of ' $\mathrm{N}$ ', it can be easily doped into carbon grid nanocomposites. Accordingly, the efficient doping of ' $\mathrm{N}$ ' into nanocomposites also helps to improve the sensing ability and that resulted in the lowest detection limit for heavy metal ions. Also, it improves the stability and magnetic properties of graphene nanocomposites [64]. In addition to that, the $\mathrm{N}$ doped graphene nanocomposites provide a higher surface area and subsequently provide more site for adsorption of heavy metal ions on the surface of nanocomposites. The combination of $\mathrm{TiO}_{2}$ and graphene followed by ' $N$ ' doping resulted in high electron mobility of the catalyst plus a larger specific surface area. This also helps to absorb and degrade the analyte [59]. Overall, the synthesized 3D, porous N-rGO@ $\mathrm{TiO}_{2}$ nanocomposites demonstrate good sensing ability and excellent performance, which are much essential in the protection of the ecosystem.

\section{Conclusions}

In summary, the green synthesis of N-rGO@ $\mathrm{TiO}_{2}$ nanocomposite is a single-step, facile, economical and less time-consuming method. The Gossypium hirsutum seeds are a good source of ' $N$ ' containing amino acid and proteins, which provide the $\mathrm{N}$ doping. They also reduce the Go and stabilize the nanocomposites. Concisely, the reported method simultaneously resulted in the eco-friendly synthesis of the N-rGO@ $\mathrm{TiO}_{2}$ nanocomposite. This nanocomposite accomplished an exceptional probe for the detection of $\mathrm{Pb}^{2+}, \mathrm{Hg}^{2+}$ and $\mathrm{Cr}$ (VI) with $50 \mathrm{nM}, 15 \mu \mathrm{M}$ and $25 \mathrm{nM}$ lower detection limits, respectively. In addition, the analysis of heavy metals $\left(\mathrm{Pb}^{2+}, \mathrm{Hg}^{2+}, \mathrm{Cr}(\mathrm{VI})\right)$ in spiked samples using synthesized N-rGO@ $\mathrm{TiO}_{2}$ nanocomposites provided an excellent result. Besides, the application of a simple spectroscopic method with eco-friendly nanocomposites can provide an alternative costeffective tool to conventional and expensive methods for heavy metal detection in water. Overall, the findings of these investigations confirmed that the N-rGO@ $\mathrm{TiO}_{2}$ nanocomposite exhibited better $\mathrm{Pb}^{2+}, \mathrm{Hg}^{2+}$ and $\mathrm{Cr}$ 
(VI) sensing ability in water through the spectroscopic method. In the future, these nanocomposites could provide better environmental remediation.

\section{Acknowledgments}

The authors are thankful to Kavayitri Bahinabai Chaudhari North Maharashtra University (KBCNMU), Jalgaon for providing funding through the Vice-Chancellor Research Motivation Scheme (VCRMS, NMU/HA/VCRMS/Budget-2016-17/ Pharmacy-10/84/2017).

\section{Conflict of Interests}

The authors declare that no competing interest exists.

\section{References}

[1] A.K. Geim, K.S. Novoselov, The rise of graphene. Nature Materials, 2007, 6: 183-191.

[2] Y. Kopelevich, P. Esquinazi, Graphene physics in graphite, Advanced Materials, 2007, 19: 4559-4563.

[3] R. Tade, S.N. Nangare, and P.O. Patil, Fundamental aspects of graphene and its biosensing applications. Functional Composites and Structures, 2021, 3: 012001.

[4] X. Li, X. Wang, L. Zhang, et al., Chemically derived, ultrasmooth graphene nanoribbon semiconductors. Science, 2008, 319: 1229-1232.

[5] C. Stampfer, E. Schurtenberger, F. Molitor, et. al., Tunable graphene single electron transistor. Nano Letters, 2008, 8: 2378-2383.

[6] D.A. Dikin, S. Stankovich, E.J. Zimney, et al., Preparation and characterization of graphene oxide paper. Nature, 2007, 448: 457-460.

[7] Y. Xu, K. Sheng, C. Li, et al., Self-assembled graphene hydrogel via a one-step hydrothermal process. ACS Nano, 2010, 4: 4324-4330.

[8] H. Bai, K. Sheng, P. Zhang, et al., Graphene oxide/ conducting polymer composite hydrogels. Journal of Materials Chemistry, 2011, 21: 18653-18658.

[9] Y. Xie, S. Xu, Z. Xu, et al., Interface-mediated extremely low thermal conductivity of graphene aerogel. Carbon, 2016, 98: 381-390.

[10] L. Xu, G. Xiao, C. Chen, et al., Superhydrophobic and superoleophilic graphene aerogel prepared by facile chemical reduction. Journal of Materials Chemistry A, 2015, 3: 7498-7504.

[11] M.A. Worsley, P.J. Pauzauskie, T.Y. Olson, et al., Synthesis of graphene aerogel with high electrical conductivity. Journal of the American Chemical Society, 2010, 132: 14067-14069.

[12] J.L. Vickery, A.J. Patil, and S. Mann, fabrication of graphene-polymer nanocomposites with higher-order three-dimensional architectures. Advanced Materials, 2009, 21: 2180-2184.

[13] W. Gao, L.B. Alemany, L. Ci, et al., New insights into the structure and reduction of graphite oxide. Nature chemistry, 2009, 1: 403-408.

[14] J. Liu, H. Bai, Y. Wang, et al., Self-assembling $\mathrm{TiO}_{2}$ nanorods on large graphene oxide sheets at a two-phase interface and their anti-recombination in photocatalytic applications. Advanced Functional Materials, 2010, 20: 4175-4181.

[15] E. Gao, W. Wang, M. Shang, et al., Synthesis and enhanced photocatalytic performance of graphene- $\mathrm{Bi}_{2} \mathrm{WO}_{6}$ composite. Physical Chemistry Chemical Physics, 2011, 13: 2887-2893.

[16] Y.H. Ng, A. Iwase, A. Kudo, et al., Reducing graphene oxide on a visible-light $\mathrm{BiVO}_{4}$ photocatalyst for an enhanced photoelectrochemical water splitting. The Journal of Physical Chemistry Letters, 2010, 1: 26072612.

[17] T. Ramanathan, A. Abdala, S. Stankovich, et al., Functionalized graphene sheets for polymer nanocomposites. Nature Nanotechnology, 2008, 3: 327331.

[18] T. Szabó, O. Berkesi, P. Forgó, et al., Evolution of surface functional groups in a series of progressively oxidized graphite oxides. Chemistry of Materials, 2006, 18: 27402749.

[19] X. Li, H. Wang, J.T. Robinson, et al., Simultaneous nitrogen doping and reduction of graphene oxide. Journal of the American Chemical Society, 2009, 131: 1593915944.

[20] F. Kim, L.J. Cote, and J. Huang, Graphene oxide: Surface activity and two-dimensional assembly. Advanced Materials, 2010, 22: 1954-1958.

[21] K.A. Mkhoyan, A.W. Contryman, J. Silcox, et al., Atomic and electronic structure of graphene-oxide. Nano letters, 2009, 9: 1058-1063.

[22] M. Agharkar, S. Kochrekar, S. Hidouri, et al., Trends in green reduction of graphene oxides, issues and challenges: A review. Materials Research Bulletin, 2014, 59: 323 328.

[23] S. Thakur, N. Karak, Alternative methods and naturebased reagents for the reduction of graphene oxide: A review. Carbon, 2015, 94: 224-242.

[24] J. Gao, F. Liu, Y. Liu, et al., Environment-friendly method to produce graphene that employs vitamin $\mathrm{C}$ and amino acid. Chemistry of Materials, 2010, 22: 2213-2218.

[25] Y. Wang, Z. Shi, and J. Yin, Facile synthesis of soluble graphene via a green reduction of graphene oxide in tea solution and its biocomposites. ACS Applied Materials \& Interfaces, 2011, 3: 1127-1133.

[26] C. Zhu, S. Guo, Y. Fang, et al.,, Reducing sugar: new functional molecules for the green synthesis of graphene nanosheets, ACS Nano, 2010, 4: 2429-2437.

[27] P. Zhang, T. Tachikawa, M. Fujitsuka, et al., Efficient charge separation on 3D architectures of $\mathrm{TiO}_{2}$ mesocrystals packed with a chemically exfoliated $\mathrm{MoS}_{2}$ shell in synergetic hydrogen evolution. Chemical Communications, 2015, 51: 7187-7190.

[28] Y. Agrawal, G. Kedawat, P. Kumar, et al., Highperformance stable field emission with ultralow turn on voltage from rGO conformal coated $\mathrm{TiO}_{2}$ nanotubes 3D arrays. Scientific Reports, 2015, 5: 11612.

[29] A.L. Linsebigler, G. Lu, and J.T. Yates Jr, Photocatalysis on $\mathrm{TiO}_{2}$ surfaces: principles, mechanisms, and selected results. Chemical Reviews, 1995, 95: 735-758.

[30] W. Han, C. Zang, Z. Huang, et al., Enhanced photocatalytic activities of three-dimensional graphenebased aerogel embedding $\mathrm{TiO}_{2}$ nanoparticles and loading $\mathrm{MoS}_{2}$ nanosheets as Co-catalyst. International Journal of Hydrogen Energy, 2014, 39: 19502-19512.

[31] F. Wu, W. Liu, J. Qiu, et al., Enhanced photocatalytic degradation and adsorption of methylene blue via $\mathrm{TiO}_{2}$ nanocrystals supported on graphene-like bamboo charcoal. Applied Surface Science, 2015, 358: 425-435.

[32] L.L. Tan, W.J. Ong, S.P. Chai, et al., Visible-light-active 
oxygen-rich $\mathrm{TiO}_{2}$ decorated 2D graphene oxide with enhanced photocatalytic activity toward carbon dioxide reduction. Applied Catalysis B: Environmental, 2015, 179: $160-170$.

[33] W. Yan, F. He, S. Gai, et al., A novel 3D structured reduced graphene oxide/ $/ \mathrm{TiO}_{2}$ composite: Synthesis and photocatalytic performance. Journal of Materials Chemistry A, 2014, 2: 3605-3612.

[34] W. Wang, J. Yu, Q. Xiang, et al., Enhanced photocatalytic activity of hierarchical macro/mesoporous $\mathrm{TiO}_{2}$-graphene composites for photodegradation of acetone in air. Applied Catalysis b: Environmental, 2012, 119: 109-116.

[35] M. Aleksandrzak, P. Adamski, W. Kukułka, et al., Effect of graphene thickness on photocatalytic activity of $\mathrm{TiO}_{2}-$ graphene nanocomposites. Applied Surface Science, 2015, 331: 193-199.

[36] K. Fujisawa, R. Cruz-Silva, K.S. Yang, et al., Importance of open, heteroatom-decorated edges in chemically doped-graphene for supercapacitor applications. Journal of Materials Chemistry A, 2014, 2: 9532-9540.

[37] M. Khandelwal, A. Kumar, One-pot environmentally friendly amino acid mediated synthesis of $\mathrm{N}$-doped graphene-silver nanocomposites with an enhanced multifunctional behavior. Dalton Transactions, 2016, 45: 5180-5195.

[38] K. Gong, F. Du, Z. Xia, et al., Nitrogen-doped carbon nanotube arrays with high electrocatalytic activity for oxygen reduction., Science, 2009, 323: 760-764.

[39] K.A. Kurak, A.B. Anderson, Nitrogen-treated graphite and oxygen electroreduction on pyridinic edge sites. The Journal of Physical Chemistry C, 2009, 113: 6730-6734.

[40] P.H. Matter, E. Wang, M. Arias, et al., Oxygen reduction reaction catalysts prepared from acetonitrile pyrolysis over alumina-supported metal particles. The Journal of Physical Chemistry B, 2006, 110: 18374-18384.

[41] P.H. Matter, L. Zhang, and U.S. Ozkan, The role of nanostructure in nitrogen-containing carbon catalysts for the oxygen reduction reaction. Journal of Catalysis, 2006, 239: 83-96.

[42] T. Iijima, K. Suzuki, Y. Matsuda, Electrodic characteristics of various carbon materials for lithium rechargeable batteries. Synthetic Metals, 1995, 73: 9-20.

[43] Y. Wu, S. Fang, and Y. Jiang, Carbon anode materials based on melamine resin. Journal of Materials Chemistry, 1998, 8: 2223-2227.

[44] F. Jaouen, M. Lefèvre, J.P. Dodelet, et al., Heat-treated $\mathrm{Fe} / \mathrm{N} / \mathrm{C}$ catalysts for $\mathrm{O}_{2}$ electroreduction: Are active sites hosted in micropores? The Journal of Physical Chemistry B, 2006, 110: 5553-5558.

[45] S. Lim, H. Elim, X. Gao, et al., Electronic and optical properties of nitrogen-doped multiwalled carbon nanotubes. Physical Review B, 2006, 73: 045402.

[46] S. Glenis, A. Nelson, and M. Labes, Formation of nitrogen doped carbon during arc-discharge of carbon rods in the presence of pyrrole. Journal of Applied Physics, 1996, 80: 5404-5407.

[47] S. Lim, H. Elim, X. Gao, et al., Electronic and optical properties of nitrogen-doped multiwalled carbon nanotubes. Physical Review B (Covering condensed matter and material physics), 2006, 73: 045402.

[48] L. Li, E. Liu, Y. Yang, et al., Nitrogen-containing carbons prepared from polyaniline as anode materials for lithium secondary batteries. Materials Letters, 2010, 64: 21152117.

[49] W.S. Hummers Jr, R.E. Offeman, Preparation of graphitic oxide. Journal of the American Chemical Society, 1958, 80: 1339-1339.

[50] Y. Wu, S. Fang, and Y. Jiang, Effects of nitrogen on the carbon anode of a lithium secondary battery. Solid State
Ionics, 1999, 120: 117-123.

[51] A.M. Massadeh, A.W.O. El-Rjoob, and S.A. Gharaibeh, Analysis of selected heavy metals in tap water by inductively coupled plasma-optical emission spectrometry after pre-concentration using chelex-100 ion exchange resin. Water, Air, \& Soil Pollution, 2020, 231: 1-14.

[52] A. Mahar, P. Wang, A. Ali, et al., Challenges and opportunities in the phytoremediation of heavy metals contaminated soils: A review. Ecotoxicology and Environmental Safety, 2016, 126: 111-121.

[53] R. Karkra, P. Kumar, B.K. Bansod, et al., Analysis of heavy metal ions in potable water using soft computing technique. Procedia Computer Science, 2016, 93: 988994.

[54] M.B. Gumpu, S. Sethuraman, U.M. Krishnan, et al., A review on detection of heavy metal ions in wateran electrochemical approach. Sensors and Actuators B: Chemical, 2015, 213: 515-533.

[55] A. Odobašić, I. Šestan, and S. Begić, Biosensors for determination of heavy metals in waters. Biosensors for Environmental Monitoring, Intech Open, 2019.

[56] N. Zaaba, K. Foo, U. Hashim, et al.,Synthesis of graphene oxide using modified hummers method: Solvent influence. Procedia Engineering, 2017, 184: 469-477.

[57] R. Chandrashekhar, B. Ram, and N.L. Bhavani, Quantitative analysis of phytochemical compounds in the cotton (Gossypium) seed xetracts; an important iommercial crop plant. Bulletin of Pure \& Applied Sciences-Botany, 2019, 38: 56-62.

[58] J.H. Patil, M.P. More, M.R. Mahajan, et al., Green synthesis of graphene based manocomposite for sensing of heavy metals. Journal of Pharmaceutical and Biological Sciences, 2019, 7: 56-62.

[59] J. Liu, K.Y. Chen, J. Wang, et al., Preparation and photocatalytic properties of $\mathrm{N}$-doped graphene/ $/ \mathrm{TiO}_{2}$ composites. Journal of Chemistry, 2020, 2020: 2928189.

[60] S.R.B. Nazri, W.W. Liu, C.S. Khe, et al., Synthesis, characterization and study of graphene oxide. AIP Conference Proceedings, AIP Publishing LLC, Dec. 6, 2018, 2045:020033.

[61] S. Ida, P. Wilson, B. Neppolian, et al., Tuning the type of nitrogen on N-RGO supported on $\mathrm{N}-\mathrm{TiO}_{2}$ under ultrasonication/hydrothermal treatment for efficient hydrogen evolution-A mechanistic overview. Ultrasonics Sonochemistry, 2020, 64: 104866.

[62] Y. Li, J. Yang, S. Zheng, et al., One-pot synthesis of $3 \mathrm{D} \mathrm{TiO}_{2}$-reduced graphene oxide aerogels with superior adsorption capacity and enhanced visible-light photocatalytic performance. Ceramics International, 2016, 42: 19091-19096.

[63] X. Shi, J. Chen, and W. Wang, Effects of $\mathrm{TiO}_{2}$ content on the microstructure, mechanical properties and photocatalytic activity of three dimensional $\mathrm{TiO}_{2}$ Graphene composite prepared by hydrothermal reaction. Materials Research Express, 2016, 3: 075602.

[64] N.N. Malinga, A.L. Jarvis, Synthesis, characterization and magnetic properties of $\mathrm{Ni}$, Co and FeCo nanoparticles on reduced graphene oxide for removal of $\mathrm{Cr}$ (VI). Journal of Nanostructure in Chemistry, 2020, 10: 55-68.

Copyright $\subset$ Pravin Onkar Patil, Sopan Namdev Nangare, Pratiksha Pramod Patil, Ashwini Ghanashyam Patil, Dilip Ramsing Patil, Rahul Shankar Tade, Arun Madhukar Patil, Prashant Krishnarao Deshmukh, and Sanjay Baburao Bari. This is an open-access article distributed under the terms of the Creative Commons Attribution License, which permits unrestricted use, distribution, and reproduction in any medium, provided the original author and source are credited. 